\title{
Predicting the properties of random inbreds and second cycle hybrids using progeny families and hierarchical selfs of a four parent cross
}

\author{
H. S. Pooni, \\ J. L. Jinks and \\ D. Yohannes
}

Department of Genetics, University of Birmingham, Birmingham B15 2TT, U.K.

\begin{abstract}
Progeny families (first selfs) and hierarchically extracted "second selfs" produced by consecutive selfing of random individuals of a four parent cross, are compared theoretically and experimentally for their accuracy and efficiency in providing estimates of predictors of the properties of random inbred lines and second cycle hybrids extractable from the same cross. In theory, both sources provide biased estimates of the predictors of means and variances both in the absence and presence of complications like epistasis, linkage dis-equilibrium and genotype $\times$ environmental interactions. While some of these biases are trivial and can be ignored for all practical purposes, those incurred by the predictors of the overall mean of random inbred lines $\left(\overline{\mathrm{D}} \mathrm{c}_{1} S_{\infty}\right)$ are often significant and they can be corrected by estimating $\overline{\mathrm{D}} \mathrm{c}_{1} \mathrm{~S}_{\infty}$ as $2 \overline{\mathrm{D}} \mathrm{c}_{1} \mathrm{~S} 1-\overline{\mathbf{D}} \mathrm{c}_{1}$ and $\frac{4}{3} \overline{\mathrm{D}} \mathrm{c}_{1} S 2-\frac{1}{3} \overline{\mathrm{D}} \mathrm{c}_{1}$, instead of as $\overline{\mathrm{D}} \mathrm{c}_{1} S 1$ and $\overline{\mathrm{D}} \mathrm{c}_{1} \mathrm{~S} 2$, respectively.

Both the "first selfs" and "second selfs" are therefore suitable sources of predictors of random inbred lines only if the above adjustments are incorporated into the predictions procedure. Predictors of second cycle hybrids, on the other hand, provide reliable and accurate predictions without adjustments.
\end{abstract}

\section{INTRODUCTION}

Pooni and Jinks (1985) have described procedures for predicting the properties of random inbred lines and second cycle hybrids that can be extracted from a double cross produced by intermating four pure breeding varieties. These procedures provide useful information on the inbreeding and outcrossing potentials of double crosses and could be used to discriminate between the more and the less productive crosses. However, a large number of generations, many of them only distantly related to the double cross itself are required for making these predictions. Consequently the breeding demands are high and particularly laborious when the material under investigation produces only one or few seeds per cross pollination. This could impose stringent restrictions on the experimental size and decrease the reliability of the results. Under these circumstances it is appropriate to ask whether simpler and smaller breeding programmes, especially the ones that rely heavily on self-pollination can be acceptable alternative sources of the predictors.

In the present paper we explore the suitability of the progeny families ("first selfs") and hierarchically extracted "second selfs" of a double cross as alternative sources of predictors. They will be compared theoretically and experimentally for their accuracy and efficiency in providing estimates of parameters that allow us to make predictions with an acceptable level of precision. Theoretically, we shall obtain the expectations of the predictor parameters and determine their biases under simple and complicated genetic situations. In practice, experimental data from two Nicotiana rustica experiments, one raised in 1981 and the other in 1983, will be analysed to make predictions and test their validity under field conditions. 
RANDOM INBREDS, SECOND CYCLE HYBRIDS AND SOURCES OF PREDICTORS

The breeding programme for producing a double cross and extracting random inbred lines and second cycle hybrids from it is presented in a diagramatic form in table 1 . The double cross $\left(D c_{1}\right)$ is obtained by crossing two unrelated single crosses $\left(F_{1}\right.$ 's) which in turn are produced by crossing two pairs of pure breeding varieties, $P_{1}$ with $P_{2}$ and $P_{3}$ with $P_{4}$. A random sample of $n$ individuals is taken from the double cross and self-pollinated to produce the "first selfs" $\left(\mathrm{Dc}_{1} \mathrm{~S} 1\right)$. Each of these $n$ progeny families $\left(\mathrm{Dc}_{1} \mathrm{~S} 1\right)$ is then advanced to the next generation $\left(\mathrm{Dc}_{1} \mathrm{~S} 2\right)$ by self-pollinating a single individual chosen at random. This procedure of random sampling and self-pollination is repeated until homozygosity is achieved.

Inbreeding by the method of single seed descent yields $\mathrm{n}$ inbred lines $\left(\mathrm{Dc}_{1} \mathrm{~S}_{\infty}\right)$ from $\mathrm{n}$ individuals of the double cross. Because the number of families remain the same from the beginning to the end of the inbreeding programme, large samples of individuals can be taken from the double cross to take advantage of unrestricted recombination in the early generations and eliminate the risks of genetic drift and gene correlations. Pairwise intermating of these inbred lines should also lead to a better representative sample of second cycle hybrids that can be extracted from the double cross.

One of the two sources that we shall use for predicting the properties of the random inbreds is the progeny families that are obtained by selfpollinating a random sample of individuals from the double cross generation. From the analysis of these "first selfs" we can estimate the overall mean $\overline{\mathrm{D}} \mathrm{c}_{1} \mathrm{~S} 1$ and the within $\left(\sigma_{\mathrm{wgDc}}^{2} \mathrm{sl}\right)$ and between family $\left(\sigma_{\mathrm{bDC}_{1} \mathrm{~S} 1}^{2}\right)$ components of genetic variation. To predict from "first selfs" alone we must therefore assume that $\overline{\mathrm{D}} \mathrm{c}_{1} \mathrm{~S} 1 \simeq \overline{\mathrm{D}} \mathrm{c}_{1} \mathrm{~S}_{\infty}$, the overall mean of the random inbreds and that $\sigma_{\mathrm{hDC}_{1} \mathrm{~S}_{1}}^{2}+$

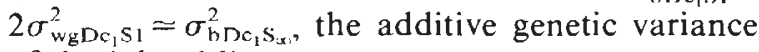
of the inbred lines.

The second source that we shall use for making predictions is the hierarchical selfs (second selfs) that are extracted from the progeny families (first selfs) described earlier. From each of the "first selfs" a minimum of two plants must be selfed to construct a hierarchical structure amongst the second selfs $\left(\mathrm{Dc}_{1} \mathrm{~S} 2\right)$. Analysis of these hierarchical families provides estimates of their overall mean

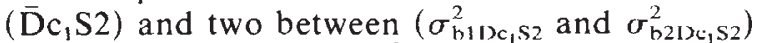
and a within family $\left(\sigma_{\mathrm{wgDc}_{1} \mathrm{~s}_{2}}^{2}\right)$ components of genetic variance. To make predictions from the "second selfs" alone we must assume that $\overline{\mathrm{D}} \mathrm{c}_{1} \mathrm{~S} 2 \approx$ $\overline{\mathrm{D}} \mathrm{c}_{1} \mathrm{~S}_{\infty}$ and $\quad \sigma_{\mathrm{b}_{1} \mathrm{Dc}_{1} \mathrm{~s}_{2}}^{2}+\sigma_{\mathrm{h} 2 \mathrm{Dc}_{1} \mathrm{~s}_{2}}^{2}+2 \sigma_{\mathrm{wgD} \mathrm{c}_{1} \mathrm{~s} 2}^{2}=$ $\sigma_{\mathrm{bDC} \mathrm{C}_{1}}^{2}$.

Table 1 Method of single seed descent and the breeding of first selfs, second selfs, random inbred lines and second cycle hybrids from a double cross that is produced by crossing four pure breeding varieties

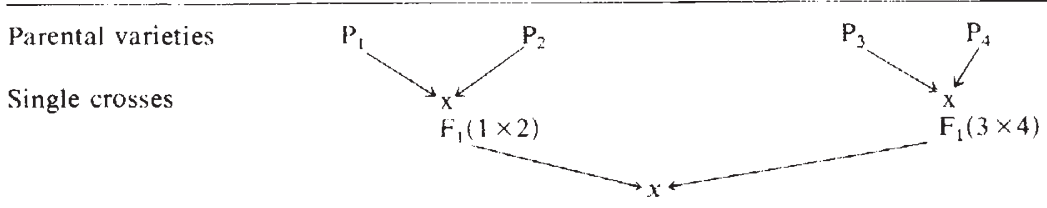

Double cross

1)

First selfs

Second selfs

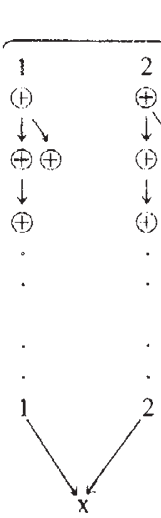

(i) (i)

3

(a)

$\downarrow$

$(\oplus)$

$\downarrow$

$\begin{array}{ccc}4 & 5 & 6 \\ \oplus & \oplus & \oplus \\ \downarrow & \downarrow \downarrow & \downarrow \downarrow \\ \downarrow & \oplus)(\oplus) & \oplus(\dagger) \\ \oplus & \downarrow & \downarrow \\ \oplus & \oplus & \oplus\end{array}$

$\cdots n$

$\cdots n$ (source 1)

...n (source 2)

$\oplus$

()

$\cdots n$

Inbreeding

by single

seed

descent

Random inbreds

Second cycle hybrids

$F_{1}(1,2)$

\section{$\stackrel{3}{\text { pairwise }}$ \\ crossing} at random

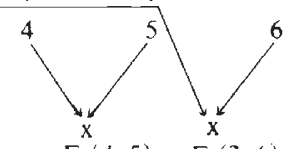

$F_{1}(4,5) \quad F_{1}(3,6)$ 
Table 2 Expected means of the parental, $F_{1}$, double cross, first selfs and second selfs generations and random samples of inbred lines and second cycle hybrids on the additive dominance model of Pooni and Jilixs (1985)

\begin{tabular}{|c|c|c|c|c|c|c|c|c|c|c|c|c|c|c|c|}
\hline \multirow[b]{2}{*}{ Source } & \multicolumn{8}{|c|}{ Additive genetic components } & \multicolumn{7}{|c|}{ Dominance components } \\
\hline & $m^{\prime}$ & $d_{1}$ & $d_{2}$ & $d_{3}$ & $d_{4}$ & $d_{5}$ & $d_{6}$ & $d_{7}$ & $h_{1}$ & $h_{2}$ & $h_{3}$ & $h_{4}$ & $h_{5}$ & $h_{6}$ & $h_{7}$ \\
\hline $\mathrm{P}_{1}$ & 1 & -1 & 1 & 1 & 1 & 1 & 1 & 1 & & & & & & & \\
\hline $\mathrm{P}_{2}$ & 1 & 1 & -1 & 1 & 1 & 1 & $\cdots \mathrm{i}$ & -1 & & & & & & & \\
\hline $\mathrm{P}_{3}$ & 1 & 1 & 1 & -1 & 1 & -1 & 1 & -1 & & & & & & & \\
\hline $\mathrm{P}_{4}$ & 1 & 1 & 1 & 1 & -1 & -1 & -1 & 1 & & & & & & & \\
\hline$F_{1}\left(P_{1} \times P_{2}\right)$ & 1 & 0 & 0 & 1 & 1 & 1 & 0 & 0 & 1 & 1 & 0 & 0 & 0 & 1 & 1 \\
\hline $\mathrm{F}_{1}\left(\mathrm{P}_{3} \times \mathrm{P}_{4}\right)$ & 1 & 1 & 1 & 0 & 0 & -1 & 0 & 0 & 0 & 0 & $\Perp$ & 1 & 0 & 1 & 1 \\
\hline Double cross $\left(\mathrm{Dc}_{1}\right)$ & 1 & $\frac{1}{2}$ & $\frac{1}{2}$ & $\frac{1}{2}$ & $\frac{1}{2}$ & 0 & 0 & 0 & $\frac{1}{2}$ & $\frac{1}{2}$ & $\frac{1}{2}$ & $\frac{1}{2}$ & 1 & $\frac{1}{2}$ & $\frac{1}{2}$ \\
\hline First selfs $\left(\mathrm{Dc}_{1} \mathrm{~S} 1\right)$ & 1 & $\frac{1}{2}$ & $\frac{1}{2}$ & $\frac{1}{2}$ & $\frac{1}{2}$ & 0 & 0 & 0 & $\frac{1}{4}$ & $\frac{1}{4}$ & $\frac{1}{4}$ & $\frac{1}{4}$ & $\frac{1}{2}$ & $\frac{1}{4}$ & $\frac{1}{4}$ \\
\hline Second selfs $\left(\mathrm{Dc}_{\mathrm{l}} \mathrm{S} 2\right)$ & 1 & $\frac{1}{2}$ & $\frac{i}{2}$ & $\frac{1}{2}$ & $\frac{i}{2}$ & 0 & 0 & 0 & $\frac{1}{8}$ & $\frac{1}{8}$ & $\frac{1}{\varepsilon}$ & $\frac{1}{8}$ & $\frac{1}{4}$ & $\frac{1}{8}$ & $\frac{1}{8}$ \\
\hline Random inbreds $\left(\mathrm{Dc}_{1} \mathrm{~S}_{\mathrm{x}}\right)$ & 1 & $\frac{1}{2}$ & $\frac{1}{2}$ & $\frac{\tilde{1}}{2}$ & $\frac{1}{2}$ & 0 & 0 & 0 & & & & & & & \\
\hline $\begin{array}{l}\text { Second cycle hybrids } \\
(\mathrm{SCH})^{*}\end{array}$ & 1 & $\frac{1}{2}$ & $\frac{1}{2}$ & $\frac{1}{2}$ & $\frac{1}{2}$ & 0 & 0 & 0 & $\frac{3}{8}$ & $\frac{3}{8}$ & है & $\frac{3}{8}$ & $\frac{1}{4}$ & $\frac{1}{4}$ & $\frac{1}{4}$ \\
\hline
\end{tabular}

* Approximated when number of genes segregating in the double cross are small.

Table 3 Contributions of the genetic and environmental parameters (defined by Pooni and Jinks 1985) to the within variances of parental varieties, $F_{1}$ 's and the double cross generation and the components of variance of the first selfs, second selfs, random inbreds and second cycle hybrids.

\begin{tabular}{|c|c|c|c|c|c|c|c|c|}
\hline \multirow[b]{2}{*}{ Source } & \multirow{2}{*}{$\begin{array}{l}\text { Environmental } \\
\text { component } \\
\mathrm{E}\end{array}$} & \multicolumn{7}{|c|}{ Additive geiretic components } \\
\hline & & $\mathrm{Vd}_{1}$ & $\mathrm{Vd}_{2}$ & $\mathrm{Vd}_{3}$ & $\mathrm{Vd}_{4}$ & $\mathrm{Vd}_{5}$ & $\mathrm{Vd}_{6}$ & $\mathrm{Vd}_{7}$ \\
\hline$P_{1}, P_{2}, P_{3}, P_{4}, F_{1}\left(P_{1} \times P_{2}\right), F_{1}\left(P_{3} \times P_{4}\right)$ & 1 & & & & & & & \\
\hline Double cross $\sigma_{\mathrm{wDc}}^{2}$ & 1 & $\frac{1}{4}$ & $\frac{1}{4}$ & $\frac{1}{4}$ & $\frac{1}{4}$ & 0 & $\frac{1}{2}$ & $\frac{1}{2}$ \\
\hline First selfs (i) between fams $\left(\sigma_{\mathrm{bD} c_{1} \mathrm{~s}_{1}}^{2}\right)$ & 0 & $\frac{1}{4}$ & $\frac{1}{4}$ & $\frac{i}{4}$ & $\frac{1}{4}$ & 0 & $\frac{1}{2}$ & $\frac{1}{2}$ \\
\hline (ii) within fams $\left(\sigma_{w \mathrm{wl}_{1} \mathrm{~s}_{1}}^{2}\right)$ & 1 & $\frac{1}{4}$ & $\frac{1}{4}$ & $\frac{1}{4}$ & $\frac{1}{4}$ & $\frac{1}{2}$ & $\frac{1}{4}$ & $\frac{1}{4}$ \\
\hline \multicolumn{9}{|l|}{ Second selfs (i) between hierarchical groups } \\
\hline$\left(\sigma_{\mathrm{B} 1 \mathrm{Dc} 1}^{2} \mathrm{~S} 2\right)$ & 0 & $\frac{1}{4}$ & $\frac{1}{4}$ & $\frac{1}{4}$ & $\frac{1}{4}$ & 0 & $\frac{1}{2}$ & $\frac{1}{2}$ \\
\hline (ii) between fams/groups $\left(\sigma_{\mathrm{b} 2 \mathrm{Dc}_{1} \mathrm{~s} 2}^{2}\right)$ & 0 & $\frac{1}{4}$ & $\frac{i}{4}$ & $\frac{1}{4}$ & $\frac{1}{4}$ & $\frac{1}{2}$ & $\frac{1}{4}$ & $\frac{1}{4}$ \\
\hline (iii) within families $\left(\sigma_{w D c_{1} s_{2}}^{2}\right)$ & 1 & $\frac{1}{8}$ & $\frac{1}{8}$ & $\frac{1}{8}$ & $\frac{1}{8}$ & $\frac{1}{4}$ & $\frac{1}{8}$ & $\frac{1}{8}$ \\
\hline Random (i) between inbred fams $\left(\sigma_{\left.\mathrm{bD} \mathrm{c}_{1} \mathrm{~S}_{\infty}\right)}\right)$ & 0 & $\frac{3}{4}$ & $\frac{3}{4}$ & $\frac{3}{4}$ & $\frac{3}{4}$ & 1 & 1 & 1 \\
\hline (ii) within inbred fams $\left(\sigma_{w D c_{1}}^{2} \alpha_{i}\right)$ & 1 & & & & & & & \\
\hline Second (i) between SCH fams $\left(\sigma_{b S C H}^{2}\right)^{*}$ & 0 & $\frac{3}{8}$ & $\frac{3}{8}$ & $\frac{3}{8}$ & $\frac{3}{8}$ & $\frac{1}{2}$ & $\frac{1}{2}$ & $\frac{1}{2}$ \\
\hline (ii) within $\mathrm{SCH}$ fams $\left(\sigma_{\mathrm{wSCH}}^{2}\right)$ & 1 & & & & & & & \\
\hline
\end{tabular}

Dominance components

Covariance components

\begin{tabular}{|c|c|c|c|c|c|c|c|c|c|c|c|c|c|}
\hline $\mathrm{Vh}_{1}$ & $\mathrm{Vh}_{2}$ & $\mathrm{Vh}_{3}$ & $\mathrm{Vh}_{4}$ & $\mathrm{Vh}_{5}$ & $\mathrm{Vh}_{6}$ & $\mathrm{Vh}_{7}$ & $\mathrm{Wdh}_{1}$ & $\mathrm{Wdh}_{2}$ & $\mathrm{Wdh}_{3}$ & $\mathrm{Wdh}_{4}$ & $\mathrm{Wdh}_{\mathrm{s}}$ & $\mathrm{Wdh}_{6}$ & $\mathrm{Wdh}_{7}$ \\
\hline $\begin{array}{l}\frac{1}{4} \\
\frac{1}{16} \\
\frac{1}{8}\end{array}$ & $\begin{array}{l}\frac{1}{4} \\
\frac{1}{16} \\
\frac{1}{8}\end{array}$ & $\begin{array}{l}\frac{1}{4} \\
\frac{1}{16} \\
\frac{1}{8}\end{array}$ & $\begin{array}{l}\frac{1}{4} \\
\frac{1}{16} \\
\frac{1}{8}\end{array}$ & $\begin{array}{l}0 \\
0 \\
\frac{1}{4}\end{array}$ & $\begin{array}{l}\frac{1}{4} \\
\frac{1}{16} \\
\frac{1}{8}\end{array}$ & $\begin{array}{l}\frac{1}{4} \\
\frac{1}{16} \\
\frac{1}{8}\end{array}$ & $\begin{array}{l}-\frac{1}{2} \\
-\frac{1}{4}\end{array}$ & $\begin{array}{l}-\frac{1}{2} \\
-\frac{1}{4}\end{array}$ & $\begin{array}{l}-\frac{1}{2} \\
-\frac{1}{4}\end{array}$ & $\begin{array}{l}-\frac{1}{2} \\
-\frac{1}{4}\end{array}$ & $\begin{array}{l}0 \\
0\end{array}$ & $\begin{array}{l}0 \\
0\end{array}$ & $\begin{array}{l}0 \\
0\end{array}$ \\
\hline $\begin{array}{l}\frac{1}{64} \\
\frac{1}{32} \\
\frac{1}{16}\end{array}$ & $\begin{array}{l}\frac{1}{64} \\
\frac{1}{32} \\
\frac{1}{16}\end{array}$ & $\begin{array}{l}\frac{1}{64} \\
\frac{1}{32} \\
\frac{1}{16}\end{array}$ & $\begin{array}{l}\frac{1}{64} \\
\frac{1}{32} \\
\frac{1}{16}\end{array}$ & $\begin{array}{l}0 \\
\frac{1}{16} \\
\frac{1}{8}\end{array}$ & $\begin{array}{l}\frac{1}{64} \\
\frac{1}{32} \\
\frac{1}{16}\end{array}$ & $\begin{array}{l}\frac{1}{64} \\
\frac{1}{32} \\
\frac{1}{16}\end{array}$ & $-\frac{1}{8}$ & $-\frac{1}{8}$ & $-\frac{1}{8}$ & $-\frac{1}{8}$ & 0 & 0 & 0 \\
\hline$\frac{15}{64}$ & $\frac{15}{64}$ & $\frac{15}{64}$ & $\frac{15}{64}$ & $\frac{1}{4}$ & $\frac{1}{4}$ & $\frac{1}{4}$ & $-\frac{3}{8}$ & $-\frac{3}{8}$ & $-\frac{3}{8}$ & $-\frac{3}{8}$ & 0 & 0 & 0 \\
\hline
\end{tabular}


Neither source is expected to provide estimates of the overall mean $(\overline{\mathrm{SCH}})$ and genetic variance $\left(\sigma_{\mathrm{bSCH}}^{2}\right)$ of the second cycle hybrids $(\mathrm{SCH})$ on its own. Thus we shall estimate the mean $\overline{\mathrm{SCH}}$ as $\frac{1}{2} \overline{\mathrm{D}} \mathrm{c}_{1} \mathrm{~S} 1+\frac{1}{4} \overline{\mathrm{F}}_{1}(1 \times 2)+\frac{1}{4} \overline{\mathrm{F}}_{1}(3 \times 4)$ or ${ }_{2}^{1} \overline{\mathrm{D}} \mathrm{c}_{1} \mathrm{~S} 1+{ }_{4}^{1} \overline{\mathrm{D}} \mathrm{c}_{1}+$ $\frac{1}{8} \overline{\mathrm{F}}_{1}(1 \times 2)+\frac{1}{8} \overline{\mathrm{F}}_{1}(3 \times 4)$ and the genetic variance

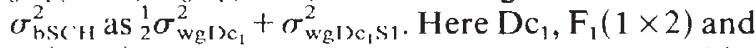
$F_{1}(3 \times 4)$ are the means of the double cross and its constituent single crosses and $\sigma_{\mathrm{wgD},}^{2}$ and $\sigma_{\mathrm{wgDc}, \mathrm{S}}^{2}$ are the genetic components of the within family variances of the double cross and "first selfs", respectively.

Theoretical expectations of the means and components of variances of the two source generations, the double cross and its constituent single crosses and the parental varieties are given alongside those of the random samples of inbreds and second cycle hybrids in tables 2 and 3 . All of these expectations with the exception of the two sources have already been derived by Pooni and Jinks (1985) for a simple additive, dominance and additive environmental model. They are listed in these tables for comparison.

Further, there are 24 different ways of producing a double cross from four pure breeding varieties. For example, we can choose to cross $F_{1}(1 \times 2)$ with $F_{1}(3 \times 4)$ or $F_{1}(1 \times 3)$ with $F_{1}(2 \times 4)$ or $F_{1}(1 \times 4)$ with $F_{1}(2 \times 3)$ to produce the double cross. Moreover we may choose the first or the second $F_{1}$, or one of their two reciprocals to be the female parent. The same choices are also available for selecting the male parent. While, however, these choices can lead to a significant difference in the mean performances of the double crosses, the properties of the random inbreds and second cycle hybrids that can be extracted from them are not expected to differ.

\section{THEORETICAL BIASES OF THE PREDICTORS}

\section{Random inbreds}

It is clear from table 2 that both sources provide biased estimates of $\bar{D} c_{1} S_{\infty}$. The estimate from the "first selfs" deviates from $\overline{\mathrm{D}} \mathrm{c}_{1} \mathrm{~S}_{\infty}$ by ${ }_{2}^{1} h^{\prime}$ where $h^{\prime}\left(={ }_{2}^{1} h_{1}+{ }_{2}^{1} h_{2}+{ }_{2}^{1} h_{3}+{ }_{2}^{1} h_{4}+h_{5}+\frac{1}{2} h_{6}+\frac{1}{2} h_{7}\right)$ is a linear dominance component equal to the difference between the double cross mean $\left(\bar{D} c_{1}\right)$ and $\bar{D} c_{1} S_{1 x}$ on a simple additive and dominance model. The "second selfs" on the other hand provide an estimate of $\bar{D} c_{1} S_{1 n}$ which is biased by $\frac{1}{4} h^{\prime}$. In the presence of non-allelic interactions these biases change from $\frac{1}{2} h^{\prime}$ and ${ }_{4}^{1} h^{\prime}$ to ${ }_{2}^{1} h^{\prime}+{ }_{4}^{1} j^{\prime}+\frac{1}{4} l^{\prime}$ and $\frac{1}{4} h^{\prime}+$ ${ }_{8}^{1} j^{\prime}+\frac{1}{16} l^{\prime}$ where $j^{\prime}$ and $l^{\prime}$ are the additive $x$ dominance and dominance $\times$ dominance interac- tion components associated with the mean of the double cross generation. The situation can be further complicated by the presence of genotype $x$ environmental interactions which could reduce or increase the biases by opposing or reinforcing the directional effects of $\frac{1}{2} h^{\prime}$ and $\frac{1}{4} h^{\prime}$ or $\frac{1}{2} h^{\prime}+\frac{1}{4} j+\frac{1}{4} l^{\prime}$ and ${ }_{4}^{1} h^{\prime}+{ }_{8}^{1} j^{\prime}+{ }_{16}^{1} l^{\prime}$ when epistasis is significant. The overall effects of these biases on the predictions will however be determined by their direction and magnitude which may differ with the pairing of the parental varieties in the single crosses.

The predictors of $\sigma_{\mathrm{hD}_{1} \mathrm{~s}_{\mathrm{x}}}^{2}$, like those of $\overline{\mathrm{D}} \mathrm{c}_{1} \mathrm{~S}_{\mathrm{\infty}}$ are also biased. Again the estimate from "first selfs" is biased approximately twice as much as that from the "second selfs" and these biases fall into two categories. A major proportion of the bias is due to the dominance component of variance which is equal to ${ }_{4}^{1}\left(\mathrm{Vh}_{1}+\mathrm{Vh}_{2}+\mathrm{Vh}_{3}+\mathrm{Vh}_{4}+2 \mathrm{Vh}_{5}+\right.$ $\mathrm{Vh}_{6}+\mathrm{Vh}_{7}$ ) (see Pooni and Jinks, 1985, for definitions of $V h_{1}$ etc. $)$ for "first selfs" and ${ }_{8}^{1}\left(V h_{1}+V h_{2}+\right.$ $V h_{3}+V h_{4}+2 V h_{5}+V h_{6}+V h_{7}$ ) for "second selfs". It is obvious that whenever dominance variation is significant both estimates of $\sigma_{\mathrm{bDc}}^{2} \mathrm{~s}_{\mathrm{x}}$ will be inflated, that from the "first selfs" more so than that from the "second selfs". The second cause of bias is the covariance component between the additive and dominance effects of those loci which have unequal gene frequencies. Its magnitude, $-\frac{1}{4}\left(W d h_{1}+W d h_{2}+W d h_{3}+W d h_{4}\right)$ and $-\frac{1}{8}\left(W d h_{1}+\right.$ $\mathrm{Wdh}_{2}+\mathrm{Wdh}_{3}+\mathrm{Wdh}_{4}$ ) respectively, however is expected to be relatively small unless there is a systematic preponderance of either plus or minus alleles over the whole range of loci.

Similarly, neither source is expected to provide true estimates of $\overline{\mathrm{D}} \mathrm{c}_{1} \mathrm{~S}_{\infty}$ and $\sigma_{\mathrm{hDc}_{1} \mathrm{~s}_{\infty}}^{2}$ in the presence of epistasis, a linkage disequilibrium and genotype $\times$ environmental interactions. However, excluding the biases described above, they are expected to provide close approximations of $\overline{D c_{1}} S_{(x)}$ and $\sigma_{b 1 c_{1}}^{2} s_{x:}$.

The first and second degree statistics that are available from the double cross and the source generations also provide weighted least squares estimates of $\overline{\mathrm{D}} \mathrm{c}_{1} \mathrm{~S}_{\alpha}$, and $\sigma_{\mathrm{hDc}_{1} \mathrm{~s}_{\alpha}}^{2}$ for comparison (see Mather and Jinks 1982 for procedures). We can estimate $\overline{\mathrm{D}} \mathrm{c}_{1} \mathrm{~S}_{1,}$ which has the expectation $m^{\prime}+$ ${ }_{2}^{1} d_{1}+{ }_{2}^{1} d_{2}+{ }_{2}^{1} d_{3}+\frac{1}{2} d_{4}=m^{\prime \prime}$ by fitting an $m^{\prime \prime}$ and $h^{\prime}$ model to the means of various generations when they have the following expectations:

$$
\begin{aligned}
\overline{\mathrm{D}} \mathrm{c}_{1} & =m^{\prime \prime}+h^{\prime} \\
\overline{\mathrm{D}} \mathrm{c}_{1} \mathrm{~S} 1 & =m^{\prime \prime}+\frac{1}{2} h^{\prime}
\end{aligned}
$$

and

$$
\overline{\mathrm{D}} \mathrm{c}_{1} \mathrm{~S} 2=m^{\prime \prime}+\frac{1}{4} h^{\prime}
$$


The model provides a comprehensive test for the presence of epistasis as a $\chi^{2}$ of goodness of fit. The $\chi_{(1)}^{2}$ takes a significant value only when nonallelic interactions are present. Further tests of epistasis can be conducted by applying the scaling tests $2 \overline{\mathrm{D}} \mathrm{c}_{1} \mathrm{~S} 1-\overline{\mathrm{D}} \mathrm{c}_{1}-\frac{1}{4}\left(\overline{\mathrm{P}}_{1}+\overline{\mathrm{P}}_{2}+\overline{\mathrm{P}}_{3}+\overline{\mathrm{P}}_{4}\right)=0$ and $2 \overline{\mathrm{D}} \mathrm{c}_{1} \mathrm{~S} 2-\overline{\mathrm{D}} \mathrm{c}_{1} \mathrm{~S} 1-\frac{1}{4}\left(\overline{\mathrm{P}}_{1}+\overline{\mathrm{P}}_{2}+\overline{\mathrm{P}}_{3}+\overline{\mathrm{P}}_{4}\right)=0$, respectively. Significant $h^{\prime}$ in the absence of epistasis also determines the magnitude and direction of bias that is associated with the predictors of $\bar{D} c_{1} S_{\infty}$.

We require six parameters, i.e., two additive genetic components, $\mathrm{D}^{\prime}\left(=\mathrm{Vd}_{1}+\mathrm{Vd}_{2}+\mathrm{Vd}_{3}+\mathrm{Vd}_{4}+\right.$ $\left.\mathrm{Vd}_{6}+\mathrm{Vd}_{7}\right)$ and $\mathrm{D}^{\prime \prime}\left(=\mathrm{Vd}_{1}+\mathrm{Vd}_{2}+\mathrm{Vd}_{3}+\mathrm{Vd}_{4}+\right.$ $\left.2 \mathrm{Vd}_{5}+\mathrm{Vd}_{6}+\mathrm{Vd}_{7}\right)$; two dominance components $\mathrm{H}^{\prime}\left(=\mathrm{Vh}_{1}+\mathrm{Vh}_{2}+\mathrm{Vh}_{3}+\mathrm{Vh}_{4}+\mathrm{Vh}_{6}+\mathrm{Vh}_{7}\right)$ and $\mathrm{H}^{\prime \prime}$ $\left(=\mathrm{Vh}_{1}+\mathrm{Vh}_{2}+\mathrm{Vh}_{3}+\mathrm{Vh}_{4}+2 \mathrm{Vh}_{5}+\mathrm{Vh}_{6}+\mathrm{Vh}_{7}\right) ;$ one covariance component $\mathrm{F}^{\prime} \quad\left(=-\mathrm{Wdh}_{1}-\mathrm{Wdh}_{2}-\right.$ $\mathrm{Wdh}_{3}-\mathrm{Wdh}_{4}$ ) and an environmental component $\mathrm{E}$; to describe the genetical and environmental differences between various components of variances. On this model each component has the following expectation:

Source

Double cross

\section{Component Model}

First selfs

$$
\sigma_{\mathrm{wDc}}^{2}
$$$$
\frac{1}{4} \mathrm{D}^{\prime}+\frac{1}{4} \mathrm{H}^{\prime}+\frac{1}{2} \mathrm{~F}^{\prime}+\mathrm{E}
$$

Second selfs

$\sigma_{\mathrm{b} 1 \mathrm{Dc}}^{2} \mathrm{~s} 1$

$\frac{1}{4} \mathrm{D}^{\prime}+\frac{1}{16} \mathrm{H}^{\prime}+\frac{1}{4} \mathrm{~F}^{\prime}$

$\sigma_{\mathrm{wDc}}^{2} \mathrm{~s} 2$

$\frac{1}{4} \mathrm{D}^{\prime \prime}+\frac{1}{8} \mathrm{H}^{\prime \prime}+\mathrm{E}$

$\frac{1}{4} \mathrm{D}^{\prime}+\frac{1}{64} \mathrm{H}^{\prime}+\frac{1}{8} \mathrm{~F}^{\prime}$

$\sigma_{\mathrm{b}_{21} \mathrm{c}_{1} \mathrm{~s} 2}^{2}$

$\sigma_{\mathrm{wDc}}^{2} \mathrm{~s} 2$

$\frac{1}{4} \mathrm{D}^{\prime \prime}+\frac{1}{32} \mathrm{H}^{\prime \prime}$

$\frac{1}{8} \mathrm{D}^{\prime \prime}+\frac{1}{16} \mathrm{H}^{\prime \prime}+\mathrm{E}$

Parents and

$F_{1}$ 's

$\mathrm{E}$

Again the model provides a test of significance for each parameter and the goodness of fit of the model is tested as $\chi_{(1)}^{2}$. Component $\sigma_{\mathrm{bDc}}^{2} \mathrm{~s}_{\infty}$ is estimated by combining $\mathrm{D}^{\prime}$ and $\mathrm{D}^{\prime \prime}$ as $\frac{1}{4} \mathrm{D}^{\prime}+\frac{1}{2} \mathrm{D}^{\prime \prime}$.

\section{Second cycle hybrids}

Predictor estimates of the overall mean $(\overline{\mathrm{SCH}})$ and the generation variance $\left(\sigma_{\mathrm{bSCH}}^{2}\right)$ of second cycle hybrids contain comparatively smaller biases. The two estimates of $\overline{\mathrm{SCH}}$ that are obtained from $\frac{1}{2} \overline{\mathrm{D}} \mathrm{c}_{1} \mathrm{~S} 1+\frac{1}{4} \overline{\mathrm{F}}_{1}(1 \times 2)+\frac{1}{4} \overline{\mathrm{F}}_{1}(3 \times 4)$ and ${ }_{2}^{1} \overline{\mathrm{D}} \mathrm{c}_{1} \mathrm{~S} 1+$ $\frac{1}{4} \overline{\mathrm{D}} \mathrm{c}_{1}+{ }_{8}^{1} \overline{\mathrm{F}}_{1}(1 \times 2)+\frac{1}{8} \overline{\mathrm{F}}_{1}(3 \times 4)$ differ theoretically from $\overline{\mathrm{SCH}}$ by $\frac{1}{8}\left(h_{6}+h_{7}\right)$ and $\frac{1}{8}\left(2 h_{5}+h_{6}+h_{7}\right)$, respectively. The distortions due to these biases are therefore expected to be negligible unless the dominance components $h_{5}, h_{6}$ and $h_{7}$ have unusually large magnitudes and take the same sign. The biases incurred by the estimate of the variance component, $\frac{1}{64}\left(\mathrm{Vh}_{1}+\mathrm{Vh}_{2}+\mathrm{Vh}_{3}+\mathrm{Vh}_{4}\right)-\frac{1}{8}\left(\mathrm{Wdh}_{1}+\right.$ $\left.\mathrm{Wdh}_{2}+\mathrm{Wdh}_{3}+\mathrm{Wdh}_{4}\right)$, are minor and can be ignored.

\section{EXPERIMENTS AND RESULTS}

Two experiments, one for making predictions and the other for testing the validity of predictions under field conditions were conducted during 1981 and 1983, respectively. The material in the prediction experiment consisted of four Nicotiana rustica varieties $V_{1}, V_{5}, V_{2}$ and $V_{12}$, single crosses $F_{1}(1 \times 5)$ and $F_{1}(2 \times 12)$ and their reciprocals, $F_{1}(1 \times 5) \times$ $F_{1}(2 \times 12)$ and $F_{1}(2 \times 12) \times F_{1}(1 \times 5)$ reciprocals of the double cross and the "first" and "second" selfed generations extracted from the double cross by hierarchical selfing. Sixteen families of a full diallel produced from the parental varieties by pairwise crossing and selfing, four reciprocals $\mathrm{F}_{1}(1 \times 5) \times \mathrm{F}_{1}(2 \times 12), \mathrm{F}_{1}(2 \times 12) \times \mathrm{F}_{1}(1 \times 5), \mathrm{F}_{1}(5 \times$ 1) $\times F_{1}(12 \times 2)$ and $F_{1}(12 \times 2) \times F_{1}(5 \times 1)$ of the double cross generation and $120 \mathrm{Dc}_{1} \mathrm{~S} 6$ inbred lines produced from the double cross by the method of single seed descent constituted the experimental material for the assessment experiment. The inbred lines grown in the assessment experiment and the "first selfs" and "second selfs" raised in the prediction experiment were extracted from equal numbers of plants taken at random from the reciprocals $F_{1}(1 \times 5) \times F_{1}(2 \times 12)$ and $F_{1}(2 \times 12) \times F_{1}(1 \times 5)$ of the double cross. Further details of the structure and dimensions of these experiments are given in table 4.

The material in both experiments was individually randomised in single blocks. Individual plants were scored for height at 4 and 6 weeks $\left(\mathrm{H}_{4}\right.$ and $\left.\mathrm{H}_{6}\right)$ after transplanting in the field, flowering time from an arbitrary date (FT), height at the time of flowering (HFT), length (LL) and width (LW) of the largest leaf blade and final plant height $(\mathrm{FH})$ at the end of the season. All characters were recorded in centimetres (to the nearest $\frac{1}{2} \mathrm{~cm}$ ) except flowering time which was recorded in days. The data were processed through the University's Multics Computer to obtain the means and variances of all generations and carry out analyses of variance wherever appropriate.

The overall means of various generations obtained by averaging over reciprocals whenever reciprocal differences were significant, are given for the seven characters in table 5. To make predictions from the "first selfs" and "second selfs" alone we must assume that their means provide appropriate estimates of $\bar{D} c_{1} S_{\infty}$, the overall mean of the random inbreds that can be extracted from the double cross. To establish, however, the direction and magnitude of biases incurred by each of these estimates and to test the adequacy of a simple additived dominance model, we obtain weighted 
Table 4 Structure and dimensions of the prediction and assessment experiments conducted during 1981 and 1983, respectively

\begin{tabular}{|c|c|c|c|c|}
\hline Material & Details & $\begin{array}{l}\text { No. of } \\
\text { families }\end{array}$ & Family size & Total plants \\
\hline \multicolumn{5}{|c|}{ (a) Prediction Experiment (1981) } \\
\hline 1. Parents & $\mathrm{V}_{1}, \mathrm{~V}_{5}, \mathrm{~V}_{2}$ and $\mathrm{V}_{12}$ & 4 & 30 & 120 \\
\hline 2. Single crosses & $\begin{array}{l}F_{1}(1 \times 5), F_{1}(5 \times 1) \\
F_{1}(2 \times 12) \text { and } F_{1}(12 \times 2)\end{array}$ & 4 & 30 & 120 \\
\hline 3. Double crosses & $\begin{array}{l}F_{1}(1 \times 5) \times F_{1}(2 \times 12) \text { and } \\
F_{1}(2 \times 12) \times F_{1}(1 \times 5)\end{array}$ & 2 & 20 & 40 \\
\hline 4. First selfs & $\begin{array}{l}120 \text { Double cross } \\
\text { plants selfed }\left(\mathrm{Dc}_{1} \mathrm{~S}_{1}\right)\end{array}$ & 120 & 10 & 1200 \\
\hline 5. Second selfs & $\begin{array}{l}2 \text { plants selfed from } \\
\text { each of } 120 \text { first } \\
\text { selfs }\left(D_{1} S 2\right)\end{array}$ & 240 & 10 & 2400 \\
\hline \multicolumn{5}{|c|}{ (b) Assessment experiment (198.3) } \\
\hline $\begin{array}{l}\text { 1. Parents and } \\
\text { single crosses }\end{array}$ & $\begin{array}{l}\text { Full diallel of } V_{1} \text {, } \\
V_{5}, V_{2} \text { and } V_{12}\end{array}$ & 16 & 20 & 240 \\
\hline 2. Double crosses & $\begin{array}{l}F_{1}(1 \times 5) \times F_{1}(2 \times 12) \\
F_{1}(2 \times 12) \times F_{1}(1 \times 5) \\
F_{1}(5 \times 1) \times F_{1}(12 \times 2) \\
F_{1}(12 \times 2) \times F_{1}(5 \times 1)\end{array}$ & 4 & 25 & 100 \\
\hline 3. Random inbreds & $120 \mathrm{Dc}_{1}$ S6 families & 120 & 10 & 1200 \\
\hline
\end{tabular}

least squares estimates of parameters $m^{\prime \prime}$ and $h^{\prime}$ and apply the scaling tests described in the previous section. The predictor estimates of $\overline{\mathrm{SCH}}$, the overall mean of the second cycle hybrids are obtained for each character by substituting the values of the relevant means in the formulae ${ }_{2}^{1} \overline{\mathrm{D}} \mathrm{c}_{1} \mathrm{~S} 1+\frac{1}{4} \overline{\mathrm{F}}_{1}(1 \times 5)+\frac{1}{4} \overline{\mathrm{F}}_{1}(2 \times 12)$ and ${ }_{2}^{1} \overline{\mathrm{D}} \mathrm{c}_{1} \mathrm{~S} 1+$ $\frac{1}{4} \overline{\mathrm{D}} \mathrm{c}_{1}+{ }_{8}^{1} \overline{\mathrm{F}}_{1}(1 \times 5)+{ }_{8}^{1} \overline{\mathrm{F}}_{1}(2 \times 12)$. These predictors and the tests of epistasis are tabulated in table 7.

The within family variances of the parental, $F_{1}$ and double cross generations and the mean squares of various items in the analyses of variance of the "first selfs" and "second selfs", are given in table 6. For the "first selfs" the significance of each between family mean square was tested against the corresponding within variance. For the "second selfs" between second selfs within first selfs mean squares were tested against the within family variances and between first selfs mean squares against the between second selfs within first selfs mean

Table 5 Mean performances of the parental $F_{1}$, double cross, first selfs and second selfs for seven characters (prediction experiment, 1981)

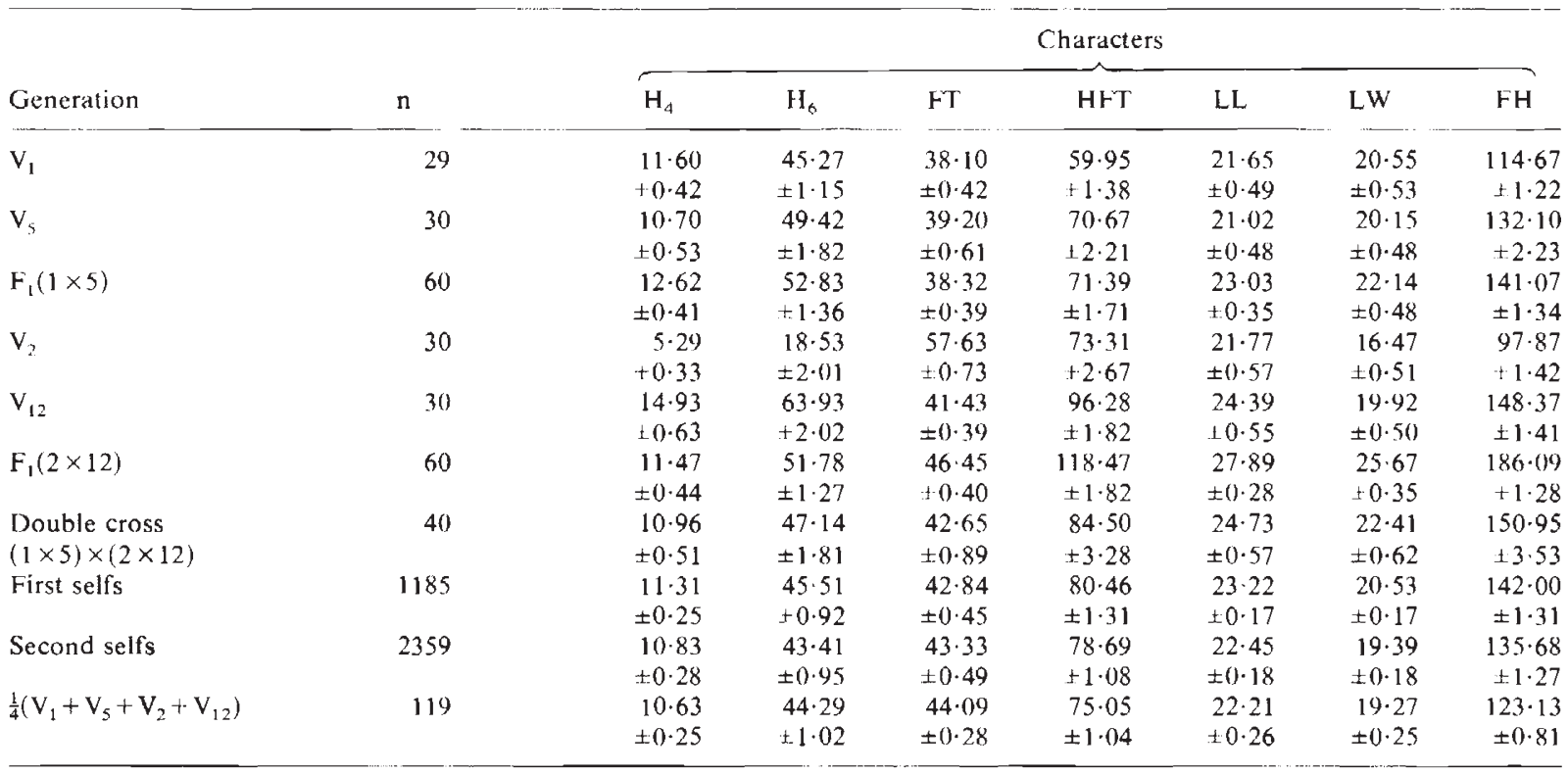


Table 6 Within family variances of the parental, single cross and double cross generations and the analyses of variance (mean squares) of the first and second selfs for the seven characters

\begin{tabular}{|c|c|c|c|c|c|c|c|c|}
\hline \multirow[b]{2}{*}{ Generation } & \multirow[b]{2}{*}{$\mathrm{df}$} & \multicolumn{7}{|c|}{ Characters } \\
\hline & & $\mathrm{H}_{4}$ & $\mathrm{H}_{6}$ & FT & HFT & $\mathrm{LL}$ & LW & $\mathrm{FH}$ \\
\hline \multicolumn{9}{|c|}{ (a) Parents and $F_{l}$ 's } \\
\hline $\mathbf{V}_{1}$ & 28 & $5 \cdot 35$ & $39 \cdot 44$ & $5 \cdot 38$ & $57 \cdot 32$ & $7 \cdot 26$ & $8 \cdot 39$ & $44 \cdot 84$ \\
\hline$V_{5}$ & 29 & $8 \cdot 55$ & $99 \cdot 05$ & $11 \cdot 34$ & $146 \cdot 77$ & $7 \cdot 05$ & $6 \cdot 90$ & $149 \cdot 31$ \\
\hline$F_{1}(1 \times 5)$ & 58 & $10 \cdot 07$ & $110 \cdot 41$ & $9 \cdot 32$ & $175 \cdot 58$ & $7 \cdot 18$ & $13 \cdot 80$ & $107 \cdot 94$ \\
\hline $\mathrm{V}_{2}$ & 29 & $3 \cdot 27$ & $121 \cdot 61$ & $15 \cdot 81$ & $213 \cdot 61$ & $9 \cdot 62$ & $7 \cdot 91$ & $60 \cdot 35$ \\
\hline$V_{12}$ & 29 & $12 \cdot 09$ & $121 \cdot 87$ & $4 \cdot 54$ & $98 \cdot 89$ & $9 \cdot 08$ & $7 \cdot 59$ & $59 \cdot 24$ \\
\hline$F_{1}(2 \times 12)$ & 58 & $11 \cdot 79$ & $96 \cdot 18$ & $9 \cdot 31$ & $198 \cdot 89$ & $4 \cdot 76$ & $7 \cdot 48$ & $98 \cdot 68$ \\
\hline $\mathrm{E}$ & 235 & $8 \cdot 52$ & 98.09 & $9 \cdot 28$ & $148 \cdot 51$ & $7 \cdot 49$ & $8 \cdot 68$ & $86 \cdot 73$ \\
\hline \multicolumn{9}{|c|}{ (b) Double cross generation } \\
\hline Double cross & 39 & $10 \cdot 26$ & $130 \cdot 96$ & $31 \cdot 39$ & $431 \cdot 10$ & $12 \cdot 95$ & $15 \cdot 19$ & $499 \cdot 14$ \\
\hline \multicolumn{9}{|c|}{ (c) First selfs of the double cross generation } \\
\hline Between families & $119^{*}$ & $76 \cdot 38$ & $1006 \cdot 25$ & $237 \cdot 79$ & $2044 \cdot 59$ & $33 \cdot 22$ & $33 \cdot 16$ & $2042 \cdot 55$ \\
\hline Within families & 1065 & $14 \cdot 12$ & $141 \cdot 26$ & $26 \cdot 03$ & $271 \cdot 19$ & $12 \cdot 42$ & $13 \cdot 11$ & $372 \cdot 85$ \\
\hline \multicolumn{9}{|c|}{ (d) Second selfs of the double cross generation } \\
\hline $\begin{array}{l}\text { Between first } \\
\text { selfs groups } \\
\text { Between second } \\
\text { selfs/first }\end{array}$ & $119^{*}$ & $190 \cdot 05$ & $2143 \cdot 99$ & $558 \cdot 48$ & $4171 \cdot 41$ & $73 \cdot 97$ & $73 \cdot 43$ & $3825 \cdot 37$ \\
\hline selfs groups & $120^{*}$ & $56 \cdot 96$ & $712 \cdot 83$ & $221 \cdot 99$ & $999 \cdot 22$ & $30 \cdot 84$ & $32 \cdot 40$ & $2070 \cdot 59$ \\
\hline $\begin{array}{l}\text { Within second } \\
\text { selfs families }\end{array}$ & 2119 & $12 \cdot 74$ & $127 \cdot 71$ & $23 \cdot 89$ & $325 \cdot 59$ & $9 \cdot 83$ & $10 \cdot 52$ & $289 \cdot 33$ \\
\hline
\end{tabular}

* Each mean square is highly significant against its appropriate error.

Table 7 Estimates of the predictors of the overall mean and genetic standard deviation of the first cycle random inbreds and second cycle hybrids and tests for the presence of non-allelic interactions

\begin{tabular}{|c|c|c|c|c|c|c|c|}
\hline \multirow[b]{2}{*}{ Source } & \multicolumn{7}{|c|}{ Characters } \\
\hline & $\mathrm{H}_{4}$ & $\mathrm{H}_{6}$ & FT & HFT & LL & LW & $\mathrm{FH}$ \\
\hline \multicolumn{8}{|c|}{ (a) Overall mean of random inbreds $\left(\bar{D} c_{1} S_{\infty}\right)$} \\
\hline First selfs & $11 \cdot 31$ & $45 \cdot 51$ & $42 \cdot 84$ & $80 \cdot 46$ & $23 \cdot 22$ & $20 \cdot 53$ & $142 \cdot 00$ \\
\hline Second selfs & $10 \cdot 83$ & $43 \cdot 41$ & $43 \cdot 33$ & $78 \cdot 69$ & $22 \cdot 45$ & $19 \cdot 39$ & $135 \cdot 68$ \\
\hline W.L.S. & $11 \cdot 08$ & $42 \cdot 40$ & $43 \cdot 01$ & $79 \cdot 95$ & $21 \cdot 69$ & $18 \cdot 36$ & $130 \cdot 61$ \\
\hline \multicolumn{8}{|c|}{ (b) Genetic s.d. of random inbreds $\left(\sigma_{\left.b D_{c}, S_{\infty}\right)}\right.$} \\
\hline First selfs & $4 \cdot 18$ & $13 \cdot 15$ & $7 \cdot 39$ & $20 \cdot 56$ & 3.65 & $3 \cdot 30$ & $18 \cdot 10$ \\
\hline Second selfs & $4 \cdot 42$ & $13 \cdot 76$ & $6 \cdot 92$ & $24 \cdot 09$ & $2 \cdot 99$ & $2 \cdot 82$ & $25 \cdot 90$ \\
\hline W.L.S. & $4 \cdot 05$ & $13 \cdot 77$ & $7 \cdot 63$ & $17 \cdot 59$ & $2 \cdot 81$ & $2 \cdot 77$ & $19 \cdot 12$ \\
\hline \multicolumn{8}{|c|}{ (c) Overall mean of second cycle hybrids $(\overline{S C H})$} \\
\hline $\begin{array}{l}\text { Single crosses } \\
\text { and first selfs }\end{array}$ & $11 \cdot 68$ & $48 \cdot 91$ & $42 \cdot 61$ & $87 \cdot 70$ & $24 \cdot 34$ & $22 \cdot 22$ & $152 \cdot 79$ \\
\hline $\begin{array}{l}\text { Single crosses, double } \\
\text { cross and first selfs }\end{array}$ & $11 \cdot 41$ & $47 \cdot 62$ & $42 \cdot 68$ & $85 \cdot 09$ & $24 \cdot 16$ & $21 \cdot 84$ & $149 \cdot 63$ \\
\hline \multicolumn{8}{|c|}{ (d) Genetic s.d. of second cycle hybrids $\left(\sigma_{\mathrm{SCH}}\right)$} \\
\hline $\begin{array}{l}\text { Double cross and } \\
\text { first selfs }\end{array}$ & $2 \cdot 54$ & $7 \cdot 72$ & $5 \cdot 27$ & $16 \cdot 25$ & $2 \cdot 89$ & $2 \cdot 77$ & $16 \cdot 92$ \\
\hline \multicolumn{8}{|c|}{ (e) Tests of epistasis } \\
\hline W.L.S. $\chi_{(1)}^{2}$ & $1.49^{\mathrm{NS}}$ & $0.46^{\mathrm{NS}}$ & $0 \cdot 18^{\mathrm{NS}}$ & $0.93^{\mathrm{NS}}$ & $0.00^{\mathrm{NS}}$ & $0 \cdot 21^{\mathrm{NS}}$ & $0 \cdot 39^{\mathrm{NS}}$ \\
\hline $2 \overline{\mathrm{D}} \mathrm{c}_{1} \mathrm{~S} 1-\overline{\mathrm{D}} \mathrm{c}_{1}-$ & $1.03^{\mathrm{NS}}$ & $-0.41^{\mathrm{NS}}$ & $-1 \cdot 06^{\mathrm{NS}}$ & $1 \cdot 37^{\mathrm{NS}}$ & $-0 \cdot 50^{\mathrm{NS}}$ & $-0.62^{\mathrm{NS}}$ & $9 \cdot 92 *$ \\
\hline$\frac{1}{4}\left(\overline{\mathrm{P}}_{1}+\overline{\mathrm{P}}_{2}+\overline{\mathrm{P}}_{3}+\overline{\mathrm{P}}_{4}\right)$ & \pm 0.76 & $\pm 2 \cdot 78$ & $\pm 1 \cdot 28$ & $\pm 4 \cdot 33$ & \pm 0.71 & \pm 0.75 & $\pm 4 \cdot 48$ \\
\hline $2 \overline{\mathrm{D}} \mathrm{c}_{1} \mathrm{~S}_{2}-\overline{\mathrm{D}} \mathrm{c}_{1} \mathrm{~S}_{1}-$ & $-0.28^{\mathrm{NS}}$ & $-2 \cdot 98^{\text {NS }}$ & $-0 \cdot 27^{\mathrm{NS}}$ & $1 \cdot 87^{\mathrm{NS}}$ & $-0.53^{\mathrm{NS}}$ & $-1 \cdot 02^{*}$ & $6 \cdot 23^{*}$ \\
\hline$\frac{1}{4}\left(\tilde{\mathrm{P}}_{1}+\overline{\mathrm{P}}_{2}+\overline{\mathrm{P}}_{3}+\overline{\mathrm{P}}_{4}\right)$ & \pm 0.67 & $\pm 2 \cdot 35$ & $\pm 1 \cdot 11$ & $\pm 3 \cdot 14$ & $\pm(1 \cdot 47$ & \pm 0.47 & $\pm 2 \cdot 98$ \\
\hline
\end{tabular}


squares whenever the latter were significant. Every one of these tests was significant at 1 per cent level of significance. These mean squares provide estimates of the between and within family components of variances that we shall use for obtaining the predictor estimates of the variances of inbred lines and second cycle hybrids. The weighted least squares estimate of $\sigma_{b \mathrm{Dc}_{1} \mathrm{~S}_{\infty}}^{2}$ of a random sample of inbreds is obtained by fitting a $\mathrm{D}^{\prime}, \mathrm{D}^{\prime \prime}, \mathrm{H}^{\prime}, \mathrm{H}^{\prime \prime}, \mathrm{F}^{\prime}$ and $\mathrm{E}$ model to these mean squares and to the variances of the double cross and parental and $F_{1}$ generations. The predictors of variances are pres-

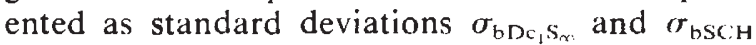
with the predictors of the overall means of random inbreds and second cycle inbreds in table 7.

We shall use these predictors of $\overline{\mathrm{D}} \mathrm{c}_{1} \mathrm{~S}_{\infty}, \overline{\mathrm{SCH}}$, $\sigma_{\mathrm{bDc}_{1} \mathrm{~s}_{\infty}}^{2}$ and $\sigma_{\mathrm{bSCH}}^{2}$ to predict the transgressive properties of random inbreds and second cycle hybrids. The standards we expect them to transgress are the largest $\left(\mathrm{St}_{\text {largest }}\right)$ and the smallest ( $\mathrm{St}_{\text {smallest }}$ ) scoring genotypes amongst the four parental varieties and two single crosses (see table 4). Following Jinks and Pooni (1976) and Toledo, Pooni and Jinks $(1984 a ; 1984 b)$ we obtain the probabilities of the transgressive segregants in the upper and lower tails of each distribution by integrating the standard normal density functions from

$$
\frac{\overline{\mathrm{S}} \mathrm{t}_{\text {largest }}-\overline{\mathrm{D}} \mathrm{c}_{1} \mathrm{~S}_{\infty}}{\sigma_{\mathrm{hD}_{\mathrm{c}} \mathrm{c}_{\mathrm{x}}}}
$$

to $+\infty$ and from $-\infty$ to

$$
\frac{\overline{\mathrm{S}} \mathrm{t}_{\text {smallest }}-\overline{\mathrm{D}} \mathrm{c}_{1} \mathrm{~S}_{\infty}}{\sigma_{\mathrm{bDc}_{1} \mathrm{~S}_{\mathrm{x}}}} ;
$$

and from

$$
\frac{\overline{\mathrm{S}} \mathrm{t}_{\text {largest }}-\overline{\mathrm{SCH}}}{\sigma_{\mathrm{bSCH}}},
$$

to $+\infty$ and from $-\infty$ to

$$
\frac{\overline{\mathrm{St}} \mathrm{smallest}-\overline{\mathrm{SCH}}}{\sigma_{\mathrm{bSCH}}}
$$

respectively. These integrals were calculated for each character separately and then multiplied by 120 , the number of random inbreds available from the double cross, to convert them into expected numbers. These are given in table 8 .

The corresponding observed numbers however are available only for random samples of inbreds because random samples of second cycle hybrids were not included in the assessment experiment

Table 8 Predicted and observed numbers (out of 120) of random inbreds and predicted numbers of second cycle hybrids that score $\geqq \mathrm{St}_{\text {largesi }}$ or $\sum \mathrm{St}_{\text {smitlest }}$

Character

Population

First cycle rádon inbreds

Second cycle hybrids

First cycle random inbreds

Second cycle hybrids

\begin{tabular}{|c|c|c|c|c|c|c|c|}
\hline First selfs & 23 & $\begin{array}{l}10 \\
(9) \dagger\end{array}$ & 3 & 4 & $\begin{array}{l}12 \\
(5)\end{array}$ & $\begin{array}{l}7 \\
(2)\end{array}$ & $\begin{array}{c}1 \\
(0)\end{array}$ \\
\hline Second selfs & 21 & $\begin{array}{c}8 \\
(7)\end{array}$ & 2 & 6 & $\begin{array}{c}4 \\
(2)\end{array}$ & $\begin{array}{l}2 \\
(1)\end{array}$ & $\begin{array}{c}3 \\
(2)\end{array}$ \\
\hline W.L.S.* & 21 & 7 & 3 & 2 & 2 & 1 & 0 \\
\hline Observed & 21 & 3 & 5 & 2 & 6 & 2 & 0 \\
\hline First selfs and $F_{1}$ 's & 12 & 3 & 0 & 3 & 13 & 13 & 3 \\
\hline $\begin{array}{l}\text { First selts, double } \\
\text { cross and } F_{1} \text { 's } \\
\qquad(\mathrm{b}) \leq \tilde{S}_{t_{\text {smallest }}}\end{array}$ & 10 & 2 & 0 & 2 & 12 & 10 & 2 \\
\hline Hirst selfs & 9 & $\begin{array}{c}3 \\
(4)\end{array}$ & 31 & 19 & $\begin{array}{l}33 \\
(51)\end{array}$ & $\begin{array}{c}13 \\
(31)\end{array}$ & $\begin{array}{c}1 \\
(3)\end{array}$ \\
\hline Second selfs & 13 & $\begin{array}{c}4 \\
(5)\end{array}$ & 27 & 26 & $\begin{array}{c}38 \\
(49)\end{array}$ & $\begin{array}{c}18 \\
(30)\end{array}$ & $\begin{array}{r}9 \\
(12)\end{array}$ \\
\hline W.L.S. & 9 & 5 & 31 & 15 & 49 & 30 & 5 \\
\hline Observed & 9 & 2 & 26 & 28 & 26 & 35 & 5 \\
\hline $\begin{array}{l}\text { First selfs and } F_{i} \text { 's } \\
\text { First selfs, double }\end{array}$ & 1 & 0 & 23 & 5 & 15 & 2 & 0 \\
\hline cross and $F_{1}$ 's & 1 & 0 & 23 & 7 & 17 & 3 & 0 \\
\hline
\end{tabular}

Source

$\begin{array}{lllllll}\mathrm{H}_{4} & \mathrm{H}_{6} & \mathrm{FT} & \mathrm{HFT} & \mathrm{LL} & \mathrm{LW} & \mathrm{FH}\end{array}$

$$
\text { (a) }>\bar{S} t_{\text {turgest }}
$$

* W.L.S. = weighted least squares.

+ Estimated from adjusted estimates of $\bar{D} c_{1} S_{x,}$ (see conclusions). 
of 1983. These observed numbers were obtained by counting the inbreds that scored either $\geqq \overline{\mathrm{St}}_{\text {largest }}$ or $\leqq \overline{\mathrm{S}} \mathrm{t}_{\text {smallest }}$. The standards used in both the prediction and assessment experiments were the same except for height at flowering time where $V_{1}$ was replaced by $\mathrm{V}_{5}$ as $\mathrm{St}_{\text {smallest }}$ in the assessment experiment. The observed numbers are listed alongside the predicted numbers in table 8 .

\section{CONCLUSIONS}

Estimates of the predictors of the properties of random inbreds and second cycle hybrids that can be extracted from a four parent cross can be compared for their reliability on two criteria. The first and most obvious criterion is whether the theoretical expectations of the predicted and observed statistics are the same. On this criterion both sources are unreliable even in the absence of complications like non-allelic interactions, linkage disequilibrium and genotype $\times$ environment interactions. Predictors estimated from the "first selfs" are however expected to differ more from the observed statistics than those from the "second selfs" because the magnitudes of their biases are twice as large (see section on "Theoretical biases of the predictors" and tables 2 and 3). On the other hand, the two sources differ only marginally if we consider the second criteria, namely, the sampling errors of the estimates of the predictors. While those from "second selfs" are always expected to have the larger sampling errors when the experimental size is the same, their relative magnitudes can be easily manipulated by altering the structure of the experiment. Consequently the relative reliabilities of the two sources are expected to differ from experiment to experiment.

Predictors of the overall mean and genetic variance of the second cycle hybrids also differ theoretically from the corresponding observed statistics. These differences, however, are exceptionally small and of ten involve no more than small fractions of the dominance components of means and variances. Furthermore, these predictors are subjected to much smaller sampling errors than those of random inbred lines (see sections on "Theoretical biases of predictors" and tables 2 and 3).

The experimental results in table 7 are in general agreement with these theoretical conclusions.
For characters $\mathrm{H}_{6}, \mathrm{LL}, \mathrm{LW}$ and $\mathrm{FH}$ the estimates of the predictors of $\overline{\mathrm{D}} \mathrm{c}_{1} \mathrm{~S}_{\infty}$ obtained from "first selfs", "second selfs" and weighted least squares analysis always rank 1,2 and 3 following the contribution of the principal bias, the dominance component $h^{\prime}$, which is positive and highly significant for these characters. For the remaining characters this ranking does not occur because neither the dominance nor epistatic component of the means was significant. Similar patterns expected between the estimates of the predictors of the variances, however, are masked by their larger standard errors. Nonetheless, it is clear that the predictors of $\sigma_{\mathrm{bDc}_{1} \mathrm{~s}_{\infty}}$ are highly consistent over all the sources for H4, H6 and FT but less so for HFT, LL, LW and FH. The largest discrepancies between the estimates are for HFT and FH and in both cases it is the estimates from "second selfs" that are unreliable. Estimates of $\overline{\mathrm{SCH}}$ on the other hand are highly consistent for all the characters.

The predictions of the numbers of random inbred lines that transgress the standards like the predictors themselves are biased in the direction of the dominance whenever it is significant (see table 8). Therefore, neither "first selfs" nor "second selfs" can be used alone to make predictions that can be considered reliable. However, the reliability of either source is improved appreciably if we substitute $2 \overline{\mathrm{D}} \mathrm{c}_{1} \mathrm{~S} 1-\overline{\mathrm{D}} \mathrm{c}_{1}$ and $\frac{4}{3} \overline{\mathrm{D}} \mathrm{c}_{1} \mathrm{~S} 2-\frac{1}{3} \overline{\mathrm{D}} \mathrm{c}_{1}$ for $\overline{\mathrm{D}} \mathrm{c}_{1} \mathrm{~S} 1$ and $\overline{\mathrm{D}} \mathrm{c}_{1} \mathrm{~S} 2$ as predictors of $\overline{\mathrm{D}} \mathrm{c}_{1} \mathrm{~S}_{\infty}$ (see predictions given in brackets in table 8 ).

\section{REFERENCES}

JINKS, J. L. AND POONI, H. S. 1976. Predicting the properties of recombinant inbred lines derived by single seed descent. Heredity 36, 253-266.

MATHER, K. AND JINKS, J. L. 1982. Biometrical Genetics. 3rd Edition. Chapman and Hall, London.

POONI, H. S. AND JINKS, J. L. 1985. Predicting the properties of first cycle inbreds and second cycle hybrids extractable from two, three and four parent crosses. Heredity, in press.

TOLEDO, J. F. F. DE, POONI, H. S. AND JINKS, J. L. $1984 a$. Predicting the properties of second cycle hybrids produced by intercrossing random samples of recombinant inbred lines. Heredity, 53, 283-292.

TOLEDO, J. F. F. DE, POONI, H. S. AND JINKS, J. L. $1984 b$. Predicting the transgressive potentials of Nicotiana rustica crosses for superior recombinant inbreds and second cycle hybrids. Proceedings of the Fifth Meeting of the Biometrics Section of Eucarpia. Hohenheim, Stuttgart 151-166. 